\title{
The oldest and youngest records of afrosoricid placentals from the Fayum Depression of northern Egypt
}

\author{
Erik R. Seiffert \\ Acta Palaeontologica Polonica 55 (4), 2010: 599-616 doi: http://dx.doi.org/10.4202/app.2010.0023
}

Tenrecs (Tenrecoidea) and goldenmoles (Chrysochloroidea) are among themost enigmatic mammals alive today. Molecular data strongly support their inclusion in the morphologically diverse clade Afrotheria, and suggest that the two lineages split near the $\mathrm{K}-\mathrm{T}$ boundary, but the only undoubted fossil representatives of each superfamily are from early Miocene ( 20 Ma) deposits in East Africa. A recent analysis of partial mandibles and maxillae of Eochrysochloris, Jawharia, and Widanelfarasia, from the latest Eocene and earliest Oligocene of Egypt, led to the suggestion that the derived "zalambdomorph" molar occlusal pattern (i.e., extreme reduction or loss of upper molar metacones and lower molar talonids) seen in tenrecoids and chrysochloroids evolved independently in the two lineages, and that tenrecoids might be derived from a dilambdomorph group of "insectivoran-grade" placentals that includes forms such as Widanelfarasia . Here I describe the oldest afrosoricid from the Fayum region, 37Ma Dilambdogale gheerbranti gen. et sp. nov., and the youngest, $\sim 30 \mathrm{Ma}$ Qatranilestes oligocaenus gen. et sp. nov. Dilambdogale is the most generalized of the Fayum afrosoricids, exhibiting relatively broad and well-developed molar talonids and a dilambdomorph arrangement of the buccal crests on the uppermolars, whereas Qatranilestes is themost derived in showing relatively extreme reduction of molar talonids. These occurrences are consistent with a scenario in which features of the zalambdomorph occlusal complex were acquired independently and gradually through the later Paleogene. Phylogenetic analysis places Dilambdogale and Widanelfarasia as sister taxa to the exclusion of crown afrosoricids, but derived features that these taxa share with early Miocene Protenrec hint at the possibility that both taxa might be stem tenrecoids. Late Paleocene Todralestes and Afrodon from Morocco are similarly placed as stem afrosoricids, indicating that African adapisoriculids (including Garatherium) might also be relevant to the origin of the tenrecoid and chrysochloroid clades.

Key words: Mammalia, Adapisoriculidae, Tenrecidae, Garatherium, Widanelfarasia, Eocene, Oligocene, Egypt.

Erik R. Seiffert [erik.seiffert@stonybrook.edu], Department of Anatomical Sciences, Stony Brook University, Stony Brook, New York, 11794-8081, USA. 
This is an open-access article distributed under the terms of the Creative Commons Attribution License (for details please see creativecommons.org), which permits unrestricted use, distribution, and reproduction in any medium, provided the original author and source are credited.

FaF Full text $(1,200.9 \mathrm{kB})$ 